\title{
Activity as a function of salinity in two species of intertidal crab, Hemigrapsus
} oregonensis and Hemigrapsus mudus

\author{
LAWRENCE H. FRANK and MERLE E. MEYER \\ Western Washington State College, Bellingham, Wash. 98225
}

The activity of Hemigrapsus oregonensis was compared to that of Hemigrapsus nudus over a 4 -min exposure to each of four salinity conditions $(0.0 \%, 33.3 \%, 66.6 \%$, and $100.0 \%$ seawater $)$. Activity increased with decreases in environmental salinity for both species. Differences between sex of $S$ and species of $S$ were nonsignificant. The results suggested that increased salinity discrepancy was aversive, that subsequent activity due to salinity variance may be part of an avoidance response, and that both species utilize the same behavioral response to salinity discrepancy.

Studies on the effect of environmental changes in marine poikilotherms have demonstrated the ability of decapod Crustacea to compensate for salinity change through ionic and osmotic regulations. Hemigrapsus nudus and Hemigrapsus oregonensis, two species of crab which inhabit the same ecological niche, are known to compensate for salinity variance by manipulation of oxygen consumption (Dehnel, 1960, 1962).

Dehnel (1960) reports that when respiration is compared at $25 \%$ seawater over various acclimation temperatures, oxygen consumption in $H$. oregonensis is greatest at low salinity. Respiration rate for $H$. nudus parallels that of $H$. oregonensis when the acclimation temperature is low $\left(5^{\circ} \mathrm{C}\right)$; but at high temperature acclimation $\left(20^{\circ} \mathrm{C}\right), H$. nudus has greatest oxygen consumption at high salinity conditions. It is conceivable, then, that differences in physiological compensation between these two species may reflect a difference in overt behavioral reactions to environmental salinity change.

Gross (1957) has suggested that increased osmotic stress, i.e., increased oxygen consumption, is the result of increased muscular activity. For instance, Pachygrapsus exhibit overt escape patterns when placed in an aqueous mileu discrepant from normal seawater concentration. Gross has further demonstrated that $P$. crassipes prefer normal seawater when exposed to concentrations varying from $50 \%$ to $150 \%$ seawater.

Symons (1964) reported that the distance traveled in response to thermal stimulation was greater in male $H$. oregonensis than in females at high environmental temperatures. This finding suggests a sex difference in locomotor activity when responding to ambient temperature. Hence, the possibility arises that a sex difference may also exist when responding to differing degrees of environmental salinity.

The present investigation was concerned with a comparison of responses to various salinities between two species of crab indigenous to the same habitat, and with determining if there was any difference in response attributable to the sex of crab.

\section{METHOD}

Source and Maintenance of Animals

Thirty-two $H$ oregonensis and 32 $H$. nudus served as Ss in the present study. The mean weights for male and female $H$. oregonensis were 5.2 and $3.4 \mathrm{~g}$, respectively, and for male and female $H$. nudus, 5.8 and $3.7 \mathrm{~g}$, respectively. The $S s$ were captured at Post Point, Bellingham, Wash., during the month of June. The animals were transported from Post point to the laboratory in a covered plastic pail filled with seawater. Within the laboratory, the Ss were maintained in approximately $12.5 \mathrm{~cm}$ of seawater in a flat-black tank, $62 \mathrm{~cm}$ long, $36 \mathrm{~cm}$ wide, and $24 \mathrm{~cm}$ high. All animals were tested $2-4 \mathrm{~h}$ after being captured. Experimental Apparatus

The experimental apparatus consisted of a gray Plexiglas chamber, $18.5 \mathrm{~cm}$ long, $8.5 \mathrm{~cm}$ wide, and $5.5 \mathrm{~cm}$ high. Two infrared photoelectric cells were mounted on the outside of the chamber, $6.5 \mathrm{~cm}$ from each end. Each light source beam passed through a separate $1.5-\mathrm{cm}$ aperature approximately $1 \mathrm{~cm}$ above the interior floor of the chamber. Disruption of either photoelectric beam activated an electronic counter. The water level in the chamber was $3.5 \mathrm{~cm}$.

Procedure and

Experimental Design

Eight $H$. nudus (four male and four female) and eight $H$. oregonensis (four male and four female) were assigned randomly to a $0.0 \%, 33.3 \%, 66.6 \%$, or $100.0 \%$ salinity condition. All salinities are expressed as percentage seawater, based on standard seawater-31.88\% salinity and $17.65 \%$ chlorinity at $25^{\circ} \mathrm{C}$ as $100.0 \%$ seawater. Salinities below $100.0 \%$ were obtained by adding distilled water to normal seawater. During experimentation, the water temperature was $6^{\circ} \pm 1^{\circ} \mathrm{C}$.

All crabs were tested individually. At the beginning of each session, the S was placed in the chamber midway between one end of the apparatus and the nearest photoelectric beam, facing the opposing end. All Ss were tested over a 4-min period.

\section{RESULTS AND DISCUSSION}

The 4 by 2 by 2 factorial analysis of variance yielded a significant salinity effect $(F=11.34, \mathrm{df}=3 / 45, \mathrm{p}<.01)$. All other effects were nonsignificant $(p>.01)$. Multiple comparisons were made, using the Duncan multiple-range test. Significant differences were obtained between all comparisons, except the $33.3 \%$ and $66.6 \%$ salinity conditions for $H$. oregonensis $(\mathrm{p}<.01)$.

Figure 1 presents the mean frequencies of responses for $H$. nudus and $H$. oregonensis over the four test salinities. As can be observed from this figure, activity in both species of shore crab increased with decreasing salinity. The present results are in agreement with the suggestion of Gross (1957) that decreased salinity (osmotic stress) should give rise to increased locomotor activity. Based on the findings of Gross and the present investigation, it seems apparent that the more divergent the salinity level from normal seawater, the more aversive it becomes. Furthermore, it is likely that the observed increase in activity was part of a behavioral escape pattern.

Although previous research has indicated differences in $H$. nudus and $H$. oregonensis in physiological

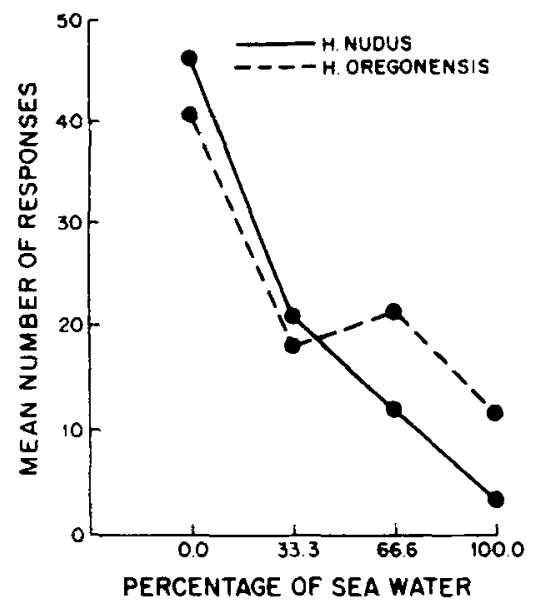

Fig. 1. Changes in activity as a function of salinity in two species of crabs. 
reaction to salinity variance, the results of the present study suggest that both species utilize the same behavioral response to salinity discrepancy. This suggestion is plausible when it is recalled that both species occupy the same habitat.

\section{REFERENCES}

DEHNEL, P. A. Effect of temperature and salinity on the oxygen consumption of two intertidal crabs. Biological Bulletin, 1960, 118, 215-249.

DEHNEL. P. A. Aspects of osmoregulation in two species of intertidal crabs. Biological Bulletin. 1962, 122, 208-227.
GROSS $w$ A behavioral mechanism for osmotic regulation in a semi-terrestrial crab. Biological Bulletin, 1957, 113 , 268-274.

SYMONS, P, E. K. Behavioral responses of the crab Hemigrapsus oregonensis to temperature, diurnal light variation, and food stimuli. Ecology, 1964. 45, $580-591$ 